\title{
DISCRETE FILLER MATERIALS FOR SURFACING IN CURRENT-CONDUCTING MOULD
}

\author{
Yu.M. KUSKOV \\ E.O. Paton Electric Welding Institute, NASU \\ 11 Bozhenko Str., 03680, Kiev, Ukraine. E-mail: office@paton.kiev.ua
}

\begin{abstract}
Discrete filler is the most promising filler material for electroslag surfacing in current-conducting mould. Particles of different dispersity can be used as such filler, namely shot, tablets, chips, powders, shorts, granules, etc. At correct selection of particle size and mass velocity of their feeding into the slag pool, a modified fine-grained structure of deposited metal with improved mechanical and other service properties can be formed. This is confirmed by positive results of surfacing the forming rolls of different mills, in particular mill 2000. The most wide-spread surfacing consumable is filler in the form of steel and cast iron shot. Shot can be mainly produced by three technological methods: mechanical fragmentation of liquid metal jet, dispersion by centrifugal forces, and dispersion by energy carrier flows. The latter method is the most wide-spread, in particular, at application of air as dispersing agent. During dispersion and further formation and cooling of pellets they are saturated with oxygen, nitrogen and hydrogen. Oxygen saturation depends on shot material, its dimensions and production method. In order to apply shot of a wider granulometric composition, fine shot as well as coarse (after fragmentation) shot can be formed into tablets by powder metallurgy. The process of their melting in the slag is similar to melting of regular-sized $0.8-2.5 \mathrm{~mm}$ shot. Chips of alloyed steels and alloys are a special kind of discrete filler. The main requirement to such filler is limitation of its dimensions and shape and absence of lubricoolant in it, contributing to a change of deposited metal composition, particularly by carbon. Other fillers, in particular, in the form of wastes from various productions (slurry wastes, wastes generated at ingot dressing, tool treatment, etc.) do not provide stable quality of deposited metal, but can be applied in development of resources-saving surfacing technologies. 4 Ref., 3 Tables, 9 Figures.
\end{abstract}

$\boldsymbol{K} \boldsymbol{e} \boldsymbol{y} \boldsymbol{w} \boldsymbol{O} \boldsymbol{r} \boldsymbol{s}:$ electroslas surfacing, current-conducting mould, shot, chips, tablets, granules

Developed at PWI design of current-conducting mould [1] in electroslag surfacing (ESS) allows application of electrodes and filler materials (billets of various cross-section, strips, discrete particles - powders, shorts, granules, shot, chips, etc.), as well as liquid filler.

The most promising are discrete fillers. Filler particles, while melting in the slag pool and being cleaned in it from impurities, come in surfacemolten and molten state into metal pool, which is then solidified into deposited metal. At correct selection of particle size and mass velocity of their feeding into the slag pool, formation of a large number of solidification centers in the liquid metal can be ensured. These centers allow modifying the deposited metal, which results in equiaxed and fine-grained structure. Such a changed structure promotes improvement of mechanical and special (wear resistance, thermal fatigue resistance) properties of metal.

As shown by our investigations on physical and mathematical simulation of the process of discrete filler transfer and melting in the form of granules of wear-resistant high-chromium cast

(C) Yu.M. KUSKOV, 2014 iron (16-30 wt.\% Cr), granules of up to $4 \mathrm{~mm}$ size can be used for circular and end face surfacing. For further increase of process efficiency (increase of mass velocity of filler feed) fractional composition in the range of $0.8-2.5 \mathrm{~mm}$ is recommended. As shown by practical experience of circular surfacing of working surfaces (bodies) of mill 2000 forming rolls (roll body diameter of approximately $1 \mathrm{~m}$ ), efficiency can reach 400$500 \mathrm{~kg} / \mathrm{h}$ without preservation of unmolten particles of the filler [2].

Shot. The most wide-spread kind of discrete surfacing material is filler in the form of steel or cast iron shot. In view of the fact that in most of the cases we deal with hardfacing, shot from high-chromium and chromium-nickel cast iron ( «ickhard» type metal) most often is used as filler.

At present, there exit the following main technologies of metal melt dispersion [3]: mechanical fragmentation of liquid metal jet, dispersion with application of centrifugal forces, and dispersion by energy carrier flows.

Mechanical fragmentation of the jet is achieved as a result of molten metal hitting a solid surface, most often a drum, partially immersed in and rotating in its cooling liquid, and 

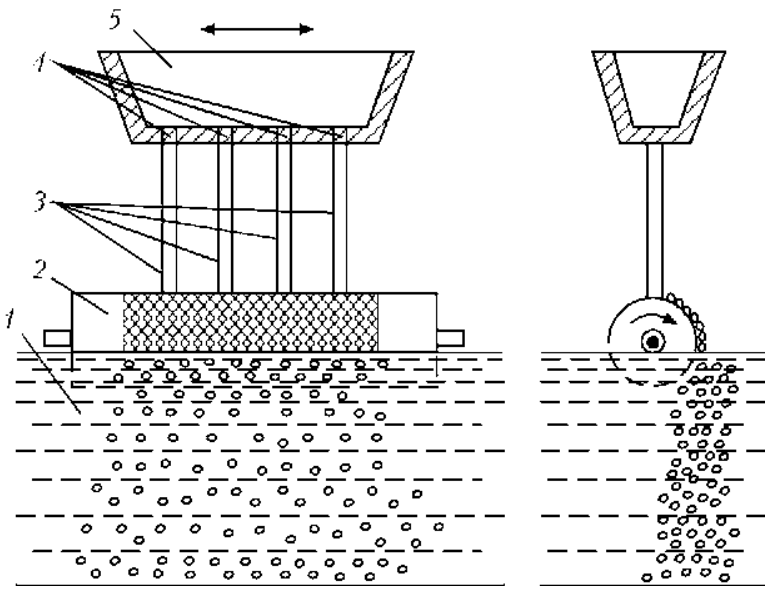

Figure 1. Schematic of producing shot by mechanical fragmentation of liquid metal jet: 1 - cooling water; 2 atomizing drum; 3 - melt jet; 4 - gate channels for melt outflow; 5 - intermediate ladle

further cooling of formed pellets in the cooling tank (Figure 1). This method is hardly suitable for manufacturing cast shot from steel or other materials with high melting temperature. At high temperature of liquid metal melt sticking to the work tool occurs, erosion or partial destruction of its working surface develops and shot quality is impaired.

Metal melt dispersion by centrifugal forces is performed as follows. Liquid metal jet stabilized as to velocity and consumption, comes to the rotating cup, and becoming accelerated under the impact of centrifugal forces, it is dispersed and thrown over the edge in the form of drops, which form granules (pellets) in flight, and then fall into the cooling tank, where they are finally cooled and solidified (Figure 2). A perforated sleeve can be used instead of the rotating cup. Dispersion by centrifugal forces yields shot of more uniform granulometric composition than in casting on a drum; yield of fine and coarse shot is reduced. The disadvantage of this technology, however, is the low resistance of the work tool.

Dispersion with application of energy carriers is the most wide-spread and promising method of producing steel and cast iron shot, as well as alloys with a high melting temperature. Used as

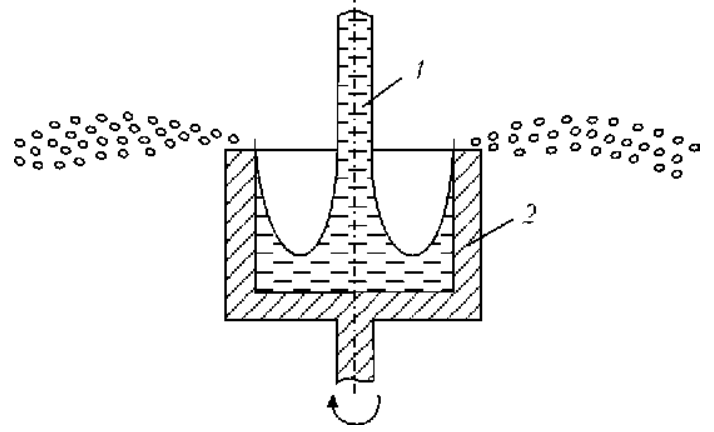

Figure 2. Schematic of producing shot by centrifugal forces: 1 - melt jet; 2 - refractory material cup

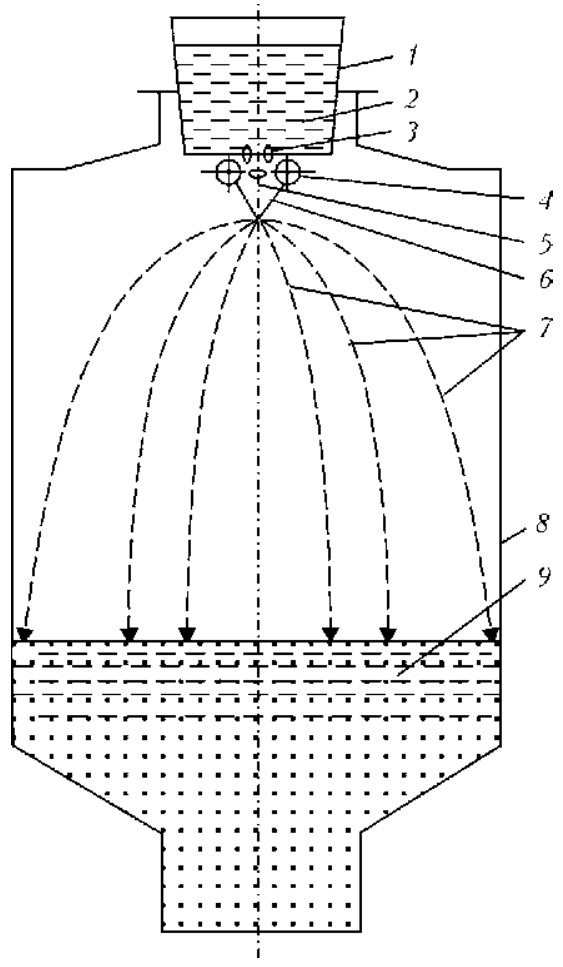

Figure 3. Schematic of producing shot using energy carriers (gas): 1 - intermediate ladle; 2 - liquid metal; 3 pouring sleeve; 4 - collector; 5 - melt jet; 6 - energy carrier flows; 7 - granule falling trajectory; 8 - dispersion chamber; 9 - cooling water

dispersion agent are various energy carriers: air, water, inert gases, steam, etc. Liquid metal jet breaking up occurs due to kinetic energy of energy carrier (Figure 3).

Some kinds of shot produced by mechanical fragmentation of liquid metal jet (shot from unalloyed cast iron), air atomization (shot from alloyed cast irons and steel), as well as other discrete filler, applied for surfacing, are shown in Figure 4. Microstructure of $2 \mathrm{~mm}$ granules (pellets) from unalloyed chromium-nickel and high-chromium cast irons is shown in Figure 5.

Passage of liquid metal jet through the air medium and further cooling in the cooling tank leads to granule oxidation and their certain saturation with hydrogen and nitrogen. Results of chemical analysis of chromium cast iron shot produced by liquid metal air atomization are shown in Table 1.

Presence of oxide films on pellet surface was examined by optical microscopy around the perimeter of microsection cross-section (Table 2). As is seen from this Table, thickness of oxide films depends on shot material, its dimensions and manufacturing method. In all the cases, the oxide film is intermittent, and does not completely cover the entire pellet surface.

Considering that no increased quantity of oxide inclusions has been found in the deposited 

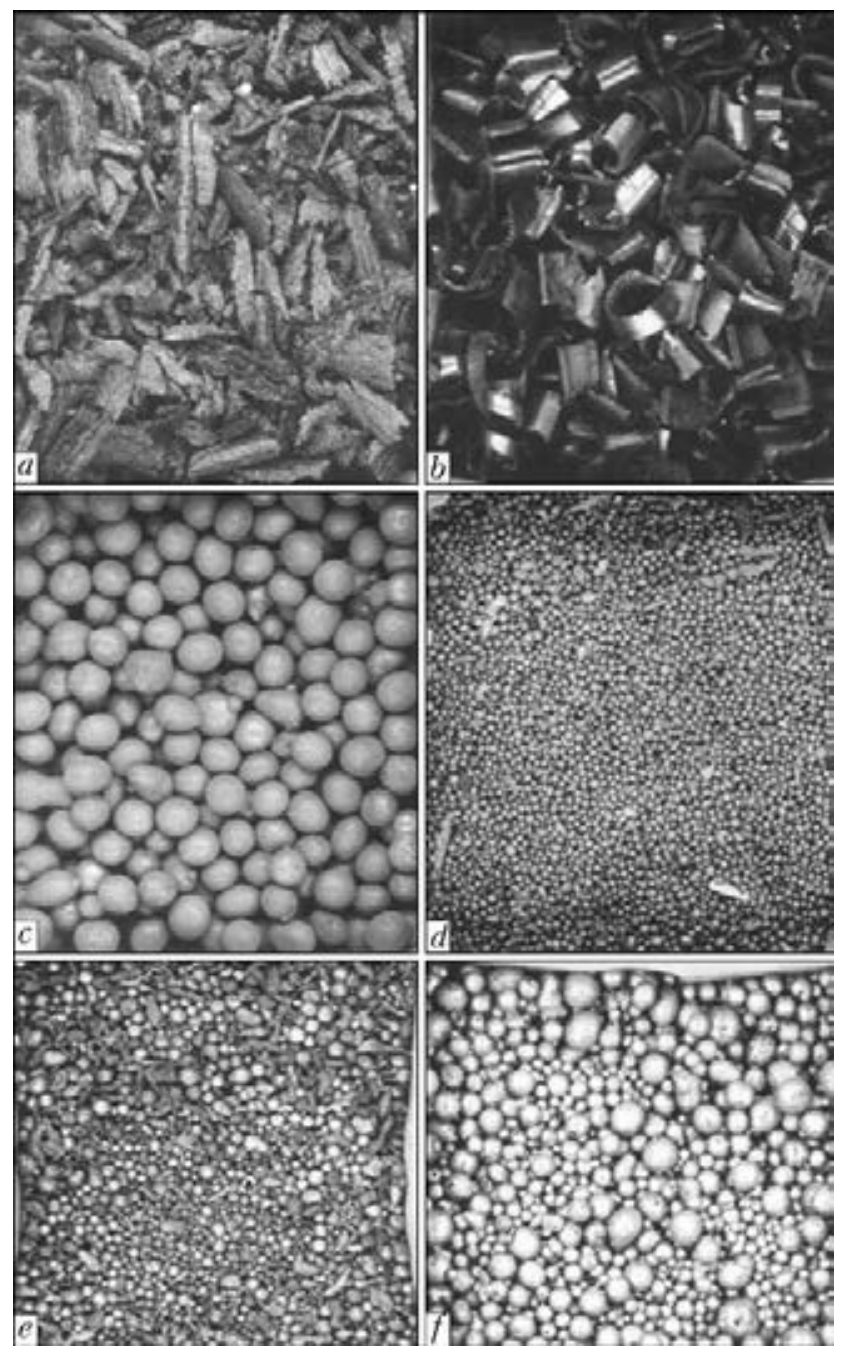

Figure 4. Some kinds of discrete filler applied in ESS in current-conducting mould: $a$ - gray cast iron chips; $b-$ R6M5 steel chips; $c-$ unalloyed cast iron shot; $d-$ R6M5K5 steel powder; $e-$ chromium cast iron shot $(16 \% \mathrm{Cr}) ; f-\mathrm{Cr}-\mathrm{Ni}$ cast iron shot

metal, it can be assumed that oxide films present on the pellet surface are assimilated by slag at filler passage through the slag layer.

Filler feed on slag pool surface is performed by dosing units. Two types of dosing units have been tried out so far: with drum-type dosing device (OB1960) making swinging movements during circular surfacing, and vibrodosimeters (Figure 6). The first type of dosing units has drawbacks associated with ensuring its stable operation, because of the possible jamming of filler, rotating drum and case, in which it rotates; certain difficulties arise at swinging displacement of current-carrying cables of dosing unit motor. The second dosing unit type is the most often used. In the absence of stringent requirements to mass velocity of filler feed, it has proved itself both in end face and in circular ESS. Figure 7 shows surfacing of mill 2000 roll with application of 4 vibrodosimeters with grit hoppers of $500 \mathrm{~kg}$ each.

Tablets. At liquid metal spraying by energy carrier flows a wide range of filler fractions is

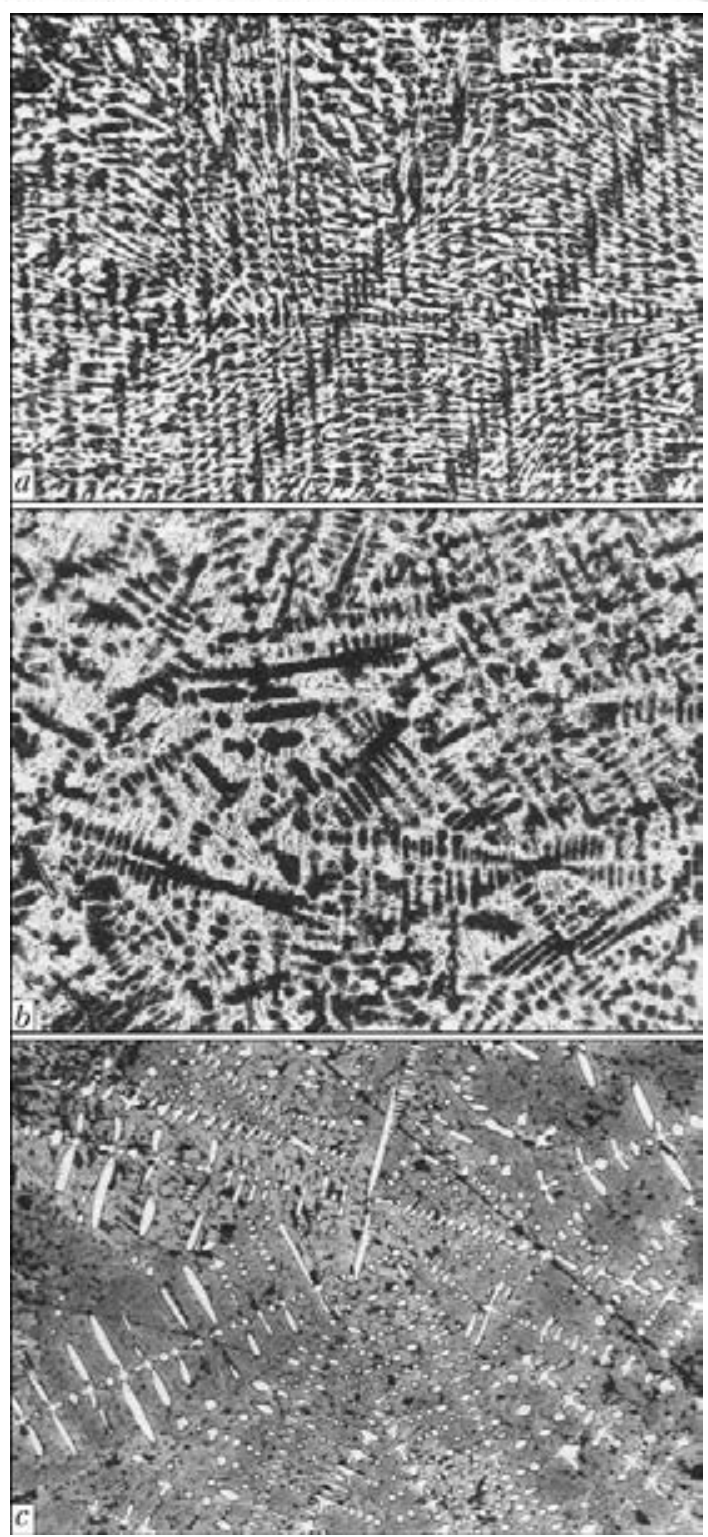

Figure 5. Microstructure $(\times 500)$ of $2 \mathrm{~mm}$ granules (pellets): $a-$ unalloyed cast iron; $b-\mathrm{Cr}-\mathrm{Ni}$ cast iron; $c-$ highchromium cast iron

obtained. So, at air atomization of high-chromium cast iron in units of «Grad» model designed by Physical-Technological Institute of Metals and Alloye of NASU the following granulometric composition is produced:

Granule size, $\mathrm{mm} \quad<0.5 \quad 0.5-1 \quad 1-3 \quad 3-5 \quad>5$

Granule quantity, \% $\quad 10.1 \quad 5.8 \quad 51.6 \quad 21.5 \quad 11.0$

Table 1. $\mathrm{N}_{2}$ and $\mathrm{H}_{2}$ content in chromium cast iron shot, produced by liquid metal air atomization, and in deposited metal, wt.\%

\begin{tabular}{|c|c|c|c||}
\hline \multirow{2}{*}{$\begin{array}{c}\text { Chemical } \\
\text { elements }\end{array}$} & \multicolumn{2}{|c|}{ Shot fraction, mm } & \multirow{2}{*}{$\begin{array}{c}\text { Deposited } \\
\text { metal }\end{array}$} \\
\cline { 2 - 3 } & $0.5-1$ & $1-3$ & 0.043 \\
\hline $\mathrm{N}_{2}$ & 0.033 & 0.05 & 0.043 \\
\hline $\mathrm{H}_{2}$ & 0.00501 & 0.00201 & 0.00062 \\
\hline
\end{tabular}


VIII INTERNATIONAL CONFERENCE «WELDING CONSUMABLES»

Table 2. Dimensions of oxide films on the surface of cast iron and $100 \mathrm{KhNM}$ steel pellets, $\mu \mathrm{m}^{*}$

\begin{tabular}{|c|c|c|c|c|c|c|c|}
\hline \multirow{3}{*}{ Shot material } & \multirow{3}{*}{$\begin{array}{l}\text { Method to produce } \\
\text { shot }\end{array}$} & \multicolumn{6}{|c|}{ Shot fractions, mm } \\
\hline & & \multicolumn{2}{|c|}{1} & \multicolumn{2}{|c|}{2} & \multicolumn{2}{|c|}{3} \\
\hline & & Thickness & Length & Thickness & Length & Thickness & Length \\
\hline Unalloyed cast iron & $\begin{array}{l}\text { Mechanical } \\
\text { fragmentation }\end{array}$ & - & - & $10-25$ & 20 & 45 & 50 \\
\hline Chromium-nickel cast iron & Air atomization & 5 & 10 & 10 & 15 & $\mathrm{~N} / \mathrm{D}$ & $\mathrm{N} / \mathrm{D}$ \\
\hline High-chromium cast iron & Same & $\mathrm{N} / \mathrm{D}$ & $\mathrm{N} / \mathrm{D}$ & $\mathrm{N} / \mathrm{D}$ & $\mathrm{N} / \mathrm{D}$ & $\mathrm{N} / \mathrm{D}$ & $\mathrm{N} / \mathrm{D}$ \\
\hline $100 \mathrm{KhNM}$ steel & $\gg$ & $10-15$ & 500 & 10 & 50 & 35 & 500 \\
\hline
\end{tabular}

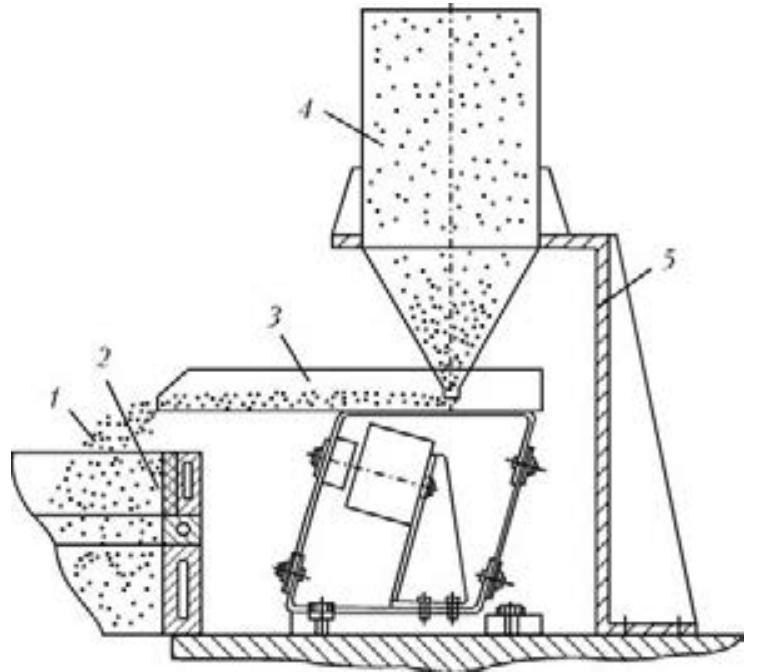

Figure 6. Schematic of vibrodosimeter applied at ESS in current-conducting mould: 1 - discrete filler; 2 - mould; 3 - feeder (working can); 4 - hopper with discrete filler; 5 - bracket

Fraction ratio can change, depending on material composition and dispersion parameters.

As is seen from these data, less than $50 \%$ of produced shot can be used for surfacing. Shot fractions, outside TU specification (0.8$2.5 \mathrm{~mm}$ ), are used as charge for subsequent melts. Here, chemical element loss increases, melting process becomes more complicated, and shot cost becomes higher. To eliminate these drawbacks of shot production, powder metallurgy methods can

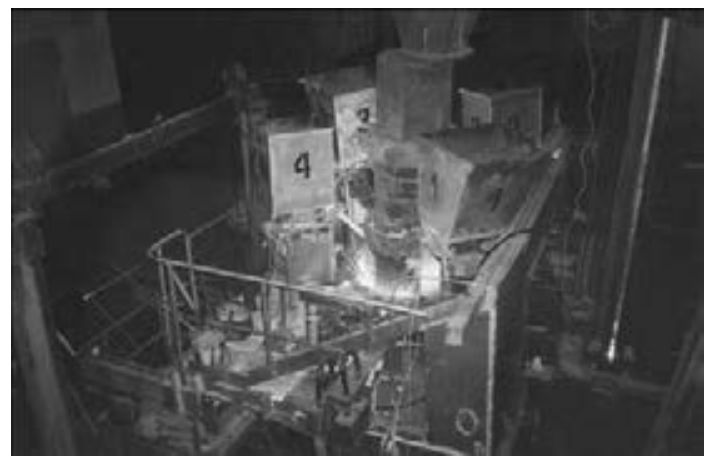

Figure 7. Surfacing mill 2000 roll with application of 4 vibrodosimeters with shot hoppers, each of $500 \mathrm{~kg}$ weight be applied. Tablets from granules of high-chromium cast iron of less than $0.8 \mathrm{~mm}$ size were pressed at Brovary State Plant of Powder Metallurgy (Ukraine). To produce relatively strong tablets, plasticizer (bakelite lacquer) was added to the mixture during its preparation. Surfacing by the produced tablets was performed in the regular mode (compared to shot surfacing). Gas evolution at tablet melting is regulated by selection of the appropriate plasticizer. Shot of more than $2.5 \mathrm{~mm}$ size can also be involved into the single-step process of producing filler surfacing material. Here, it should first be moved to the category of crushed shot with subsequent pressing of fine particles into tablets; larger fragments can be also used as surfacing filler, similar to regular shot, in the case if their dimensions are not larger than those specified by TU norms.

Figure 8 shows end face surfacing of highchromium cast iron with tablet feeding from vibrodosimeter.

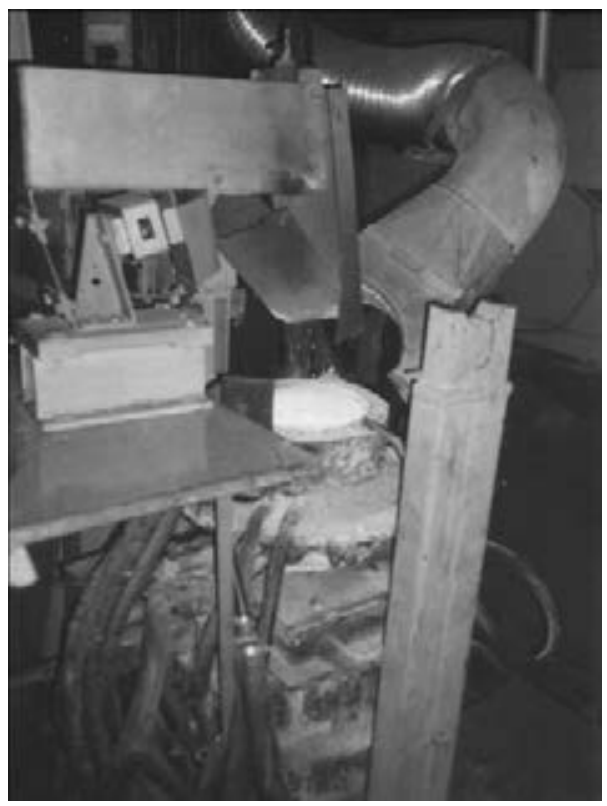

Figure 8. End face surfacing of high-chromium cast iron with tablet feeding from vibrodosimeter 
Table 3. Composition and hardness of metal deposited with chips of $15 \mathrm{Kh} 11 \mathrm{MF}$ steel at different methods of its cleaning

\begin{tabular}{||l|c|c|c|c|c||}
\hline \multirow{2}{*}{ Treatment of chips with LC before surfacing } & \multicolumn{5}{c||}{ Deposited metal composition, wt.\% } \\
\cline { 2 - 6 } & $\mathrm{C}$ & $\mathrm{Si}$ & $\mathrm{Mn}$ & $\mathrm{Cr}$ & $\mathrm{Mo}$ \\
\hline 15Kh11MF steel to GOST 5632-72 & $0.12-0.19$ & $\leq 0.50$ & $\leq 0.70$ & $10.0-11.5$ & $0.60-0.80$ \\
\hline 1. Untreated & 3.86 & 0.32 & 0.41 & 10.81 & 0.06 \\
\hline $\begin{array}{l}\text { 2. Washing in hot water with soda ash + baking } \\
\text { at } 600{ }^{\circ} \mathrm{C} \text { for 0.5 h }\end{array}$ & 0.44 & 0.22 & 0.36 & 11.20 & 0.10 \\
\hline $\begin{array}{l}\text { 3. } 5 \text { times boiling with soda ash and powdered } \\
\text { detergent }\end{array}$ & 0.28 & 0.22 & 0.27 & 10.30 & 0.66 \\
\hline \begin{tabular}{l} 
4. Washing in car wash unit \\
\hline
\end{tabular}
\end{tabular}

Table 3 (cont.)

\begin{tabular}{|c|c|c|c|c|c|c|}
\hline \multirow{2}{*}{ Treatment of chips with LC before surfacing } & \multicolumn{5}{|c|}{ Deposited metal composition, wt.\% } & \multirow{2}{*}{$\begin{array}{l}\text { Hardness, } \\
H B / H R C\end{array}$} \\
\hline & $\mathrm{V}$ & $\mathrm{Ni}$ & $\mathrm{Cu}$ & S & $\mathrm{P}$ & \\
\hline $15 \mathrm{Kh} 11 \mathrm{MF}$ steel to GOST $5632-72$ & $0.25-0.40$ & $\leq 0.60$ & $\leq 0.30$ & $\leq 0.025$ & $\leq 0.03$ & $\leq 285 / \mathrm{ND}$ \\
\hline 1. Untreated & 0.04 & 0.19 & 0.11 & 0.012 & 0.03 & $\mathrm{ND} / 54$ \\
\hline $\begin{array}{l}\text { 2. Washing in hot water with soda ash }+ \text { baking } \\
\text { at } 600{ }^{\circ} \mathrm{C} \text { for } 0.5 \mathrm{~h}\end{array}$ & 0.04 & 0.18 & 0.30 & 0.004 & 0.035 & ND / 43 \\
\hline $\begin{array}{l}\text { 3. } 5 \text { times boiling with soda ash and powdered } \\
\text { detergent }\end{array}$ & 0.30 & 0.40 & 0.15 & 0.004 & 0.027 & - \\
\hline 4. Washing in car wash unit & 0.29 & 0.34 & 0.15 & 0.003 & 0.013 & - \\
\hline
\end{tabular}

Chips. Application of chips from alloyed steels and various types of cast irons in surfacing allows considerable reduction of surfacing operation cost. This is associated with the fact that the cost of surfacing consumables is the main component in surfacing cost.

Non-spiral chips of small size $(<0.5 \times 5 \times$ $\times 5 \mathrm{~mm}$ ) produced in milling and planing of metal are used for surfacing. For a number of materials (mostly hard and brittle) chips of required size can be produced at lathing and drilling (see Figure 4).

Application of this kind of surfacing consumable is difficult for two reasons. This is presence of lubricoolant (LC) in it and complexity of organizing collection of chips by dimensions and composition. As regards chips collection, at present this problem was begun to be solved in a simpler manner, in connection with a smaller range of applied tool steels (in particular, highspeed) and smaller volume of machining of parts.

Presence of LC in the chips disturbs surfacing process stability, is detrimental to environment in connection with increased gas evolution, changes deposited metal composition (mainly, by carbon), and can affect metal quality (chiefly, because of pore formation).

Usually, chemical methods of chip treatment as well as thermal methods or their combination are used to remove LC. Table 3 gives the results of chemical analysis of metal deposited with chips from $15 \mathrm{Kh} 11 \mathrm{MF}$ steel at different methods of its cleaning.

For cast iron chips it is recommended to perform heat treatment at $800-1000{ }^{\circ} \mathrm{C}$ [4]. Such

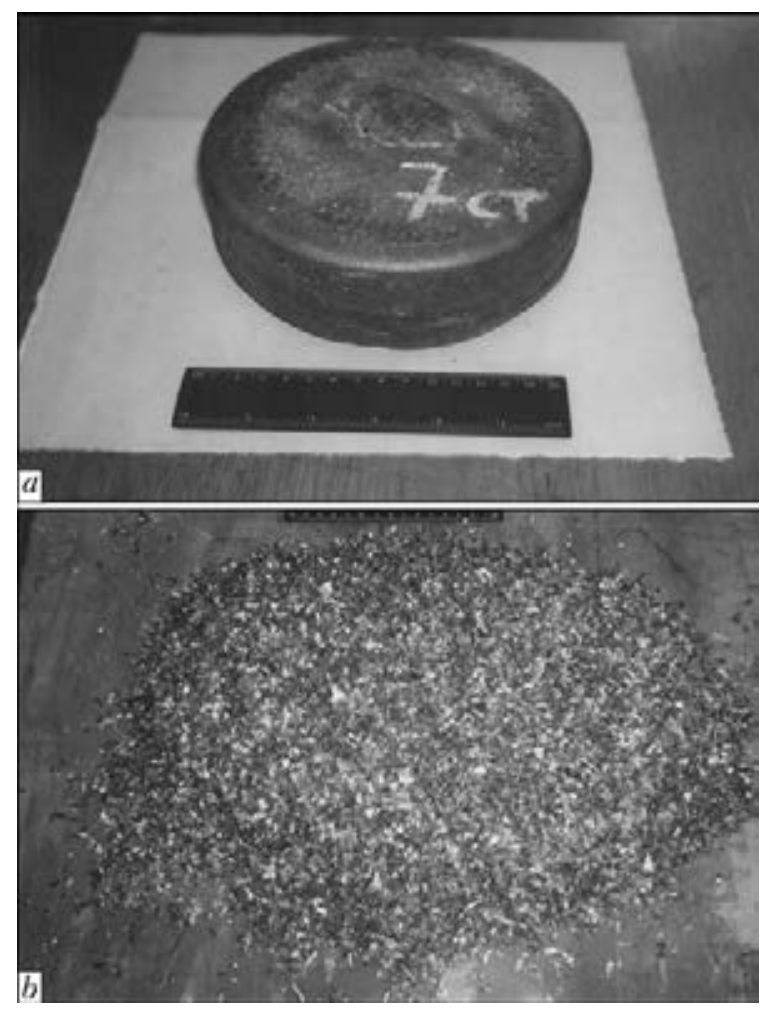

Figure 9. Appearance of molten blank $(a)$ and discrete surfacing filler - chips of $15 \mathrm{Kh} 11 \mathrm{MF}$ steel (b) (experiment 4 acc., Table 3) 
treatment ensures lowering of LC content in cast iron chips to 0.3 wt.\%.

Appearance of a billet, surfaced with chips from $15 \mathrm{Kh} 11 \mathrm{MF}$ steel, is shown in Figure 9.

In addition to the above-given main kinds of filler materials, other materials can be also used for surfacing, the application of which allows speaking about resources-saving surfacing technologies. In particular, these are slurry wastes generated at dressing of alloyed steel ingots, tool treatment, etc. Technology of surfacing with these materials is more complicated, and it is difficult to ensure a high quality of deposited metal. Application of two technological schematics is possible. The first is thorough cleaning (for instance, by magnetic separation) of filler to remove extraneous (most often non-metallic) components, and then application of the cleaned part in surfacing. In this case difficulties arise both during addition of obtained fine particles to the slag pool, and in terms of ensuring the uniformity and stability of their immersion into slag. This kind of problems is related to particle coagulation on slag pool surface and impact of slag surface tension forces. It is difficult to predict deposit quality at application of such filler. The second schematic is a two-stage one. It also envisages initial treatment (less thorough than in the first case), then remelting of cleaned filler, producing an alloyed ingot, its crushing and use of crushed filler similar to the case of crushed shot. Owing to primary slag treatment of filler, the produced ingot metal (furtheron of filler used for surfacing) has improved characteristics, both in terms of structure, and composition.

\section{Conclusions}

1. Best quality of metal, surfaced in current-conducting mould, can be achieved with application of discrete filler. The most promising kind of filler is cast shot, produced by the method of liquid metal jet dispersion by energy carrier, in particular, air.

2. To improve ESS economics, filler in the form of tablets or chips can be used in currentconducting mould. With optimization of the technology of producing such filler and methods of its preparation for surfacing, production of sound bimetal items can be guaranteed.

3. Other kinds of fillers, in particular, wastes of various productions containing alloyed metal part, lead to complication of ESS technology, but are preferable, due to being the main cost items of resources-saving processes. Without ensuring a stable high quality of the deposited metal, they, nonetheless, can be used at reconditioning of parts, the main requirement to which is cost-effectiveness.

1. Kuskov, Yu.M. (2006) Resources-saving technology of repair and manufacturing of parts by electroslag surfacing method. Tekhnologiya Mashinostroeniya, 6, 40-42.

2. Kuskov, Yu.M., Ryabtsev, I.A., Sarychev, I.S. (2004) Recovery of cast iron rollers of mill 2000 in current-carrying mould. Svarshchik, 1, 12-13.

3. Zatulovsky, S.S., Mudruk, L.A. (1988) Manufacturing and application of metallic shot. Moscow: Metallurgiya.

4. Potapov, V.V., Tsymbalov, S.D., Korostelev, A.B. et al. (2009) Heat treatment of cast-iron chips contaminated by lubricoolant. Litejn. Proizvodstvo, 11, 19-20.

Received 23.03.2014 